\title{
Degradabilidade ruminal de casca de vagem de feijão-fava (Phaseolus lunatus L.) amonizada com ureia
}

\author{
Ruminal degradability of shell of pods of the lima bean ("Phaseolus lunatus" L.) \\ ammoniated with urea
}

\author{
SILVA, Raimundo Nonato Pereira da ${ }^{1}$; ALVES, Arnaud Azevêdo ${ }^{2}$; GARCEZ, Bruno \\ Spindola $^{2}$; MOREIRA FILHO, Miguel Arcanjo ${ }^{4}$; OLIVEIRA, Maria Elizabete de ${ }^{2}$; \\ MOREIRA, Antônia Leidiana ${ }^{2}$; AZEVÊDO, Danielle Maria Machado Ribeiro ${ }^{3}$; \\ PARENTE, Henrique Nunes ${ }^{4}$
}

\footnotetext{
${ }^{1}$ Universidade Federal do Piauí, Centro de Ciências Agrárias, Departamento de Zootecnia, Teresina, Piauí, Brasil.

${ }^{2}$ Universidade Federal do Piauí, Centro de Ciências Agrárias, Programa de Pós Graduação em Ciência Animal, Teresina, Piauí, Brasil.

${ }^{3}$ Embrapa Meio-Norte, Teresina, Piauí, Brasil.

${ }^{4}$ Universidade Federal do Maranhão, Centro de Ciências Agrárias e Ambientais, Chapadinha, Maranhão, Brasil.

*Endereço para correspondência: bruno.spg@hotmail.com
}

\section{RESUMO}

Objetivou-se com esta pesquisa avaliar a degradabilidade ruminal da matéria seca, proteína bruta e fibra em detergente neutro de casca de vagem de feijão-fava (Phaseolus lunatus L.) não amonizada (controle) ou amonizada com três níveis de ureia $(2 ; 4$ e $6 \%$, com base na matéria seca). Foram utilizados três bovinos Girolandos providos de cânula ruminal, com peso vivo médio $400 \pm 5,3 \mathrm{~kg}$, cada. A amonização das cascas de feijão-fava com $6 \%$ de ureia resultou em maiores teores de proteína bruta $(15,7 \%)$ e degradabilidade potencial da proteína bruta $(91,7 \%)$. A degradação potencial da matéria seca aumentou $(\mathrm{P}<0,05)$ com $\mathrm{O}$ tempo de incubação, atingindo $85,1 \%$ às $48 \mathrm{~h}$ de incubação, embora a amonização não tenha promovido alterações relevantes na cinética de degradação ruminal deste constituinte. Quanto à cinética de degradação ruminal da fibra em detergente neutro, a amonização com $6 \%$ de ureia reduziu em cerca de $1 \mathrm{~h}$ o tempo de latência (lag time), no entanto, este efeito não influenciou os demais parâmetros de degradação da fibra em detergente neutro, com taxa de degradação compatível com as características de alimentos fibrosos. A casca de feijão-fava apresenta elevada taxa de degradação, consistindo em um alimento volumoso de boa qualidade, apesar de consistir resíduo de cultura. A amonização de casca de feijão-fava com ureia não promove melhoria na degradabilidade da matéria seca, embora proporcione elevação do teor de nitrogênio total disponível aos microrganismos do rúmen $\mathrm{e}$ melhore $\mathrm{a}$ degradabilidade da fibra em detergente neutro, sendo o nível de $6 \%$ mais indicado para o tratamento desse volumoso.

Palavras-chave: amonização, co-produto, degradação in situ, Phaseolus lunatus

\section{SUMMARY}

This study aimed to evaluate the dry matter, crude protein and neutral detergent fiber ruminal degradability of shell pods of lima bean (Phaseolus lunatus L.) ammoniated with four levels of urea $(0 ; 2 ; 4$ and $6 \%$ in dry matter basis). Three adult cattle Girolando breed, with $400 \pm 5,3 \mathrm{~kg}$ of body weight fistulated with ruminal cannula were utilized. Ammoniation of shell of pods of the lima bean as $6 \%$ urea resulted in higher crude protein content $(15.7 \%)$ of shell pods and degradability of crude protein $(91.7 \%)$. Potential degradation of dry matter 
increased $(\mathrm{P}<0.05)$ with the incubation time, reaching $85.1 \%$ at $48 \mathrm{~h}$ of incubation, although the ammoniation not promoted significant changes in ruminal degradation kinetics of this constituent. Regarding the kinetics of ruminal degradation of neutral detergent fiber, ammoniation with $6 \%$ urea decreased by approximately $1 \mathrm{~h}$ in the lag time, although no influence has verified to other parameters of neutral detergent fiber degradation, with degradation rate compatible with the characteristics of fibrous feeds (about 3\% $\mathrm{h}^{-1}$ ). The lima bean shell pods of presents high degradation rate, consisting in a bulky feed of good quality, although considered a waste of culture. Ammoniation of shell pods of lima bean with urea does not promote improvement in dry matter degradability, although result in improvement of total nitrogen available to microrganisms in the rumen, with improve the neutral detergent fiber degradability, and the level of $6 \%$ more suitable for treatment in this bulky.

Keywords: ammoniation, coproduct, in situ degradation, Phaseolus lunatus

\section{INTRODUÇÃO}

O elevado custo de produção nas diferentes fases do processo produtivo é um dos obstáculos ao desenvolvimento da produção de ruminantes, principalmente quando se utilizam ingredientes concentrados, além das variações no valor nutritivo das pastagens no decorrer do ano (SULTANA et al., 2015). Assim, resíduos de culturas, como restolhos e palhadas, deve ser avaliados e utilizados principalmente como opção para uso em períodos de déficit de alimentos.

No entanto, os principais constituintes da composição química desses alimentos, em comparação às fontes convencionais de origem vegetal, consistem de carboidratos estruturais, principalmente celulose e hemicelulose, assim como do elevado teor de lignina. Nesse sentido, os tratamentos químicos, com agentes hidrolíticos, são alternativas viáveis para melhoria o valor nutritivo desses volumosos de baixa qualidade, sendo os mais utilizados os hidróxidos de sódio, de potássio, de cálcio e de amônio, a amônia anidra e a ureia (PIRES et al., 2010).

A família Fabaceae compreende cerca de 19.400 espécies, distribuídas em 740 gêneros e está concentrada nas regiões tropicais e subtropicais (AMARAL et al., 2015). Considerando-se as perspectivas de aumento de produção e produtividade e a importância da cultura do feijão-fava (Phaseolus lunatus L.) no Brasil, principalmente para a agricultura familiar, justifica-se o estudo do potencial das cascas de vagens como resíduo de cultura para a alimentação de ruminantes, em especial na região Nordeste, onde é grande a escassez de alimentos no período seco do ano.

As características químicas da planta são fatores que exercem grande influência sobre os efeitos da amonização de volumosos, assim, pesquisas que identifiquem o potencial nutritivo de alimentos fibrosos, como resíduos de produção agrícola, e a possibilidade de melhoria da qualidade, poderão gerar tecnologias adequadas a uma melhor oferta desses alimentos. Neste sentido, objetivou-se com esta pesquisa avaliar o efeito da amonização da casca de feijãofava, quanto às alterações nos parâmetros da cinética de degradação ruminal in situ da matéria seca, proteína bruta e fibra em detergente neutro.

\section{MATERIAL E MÉTODOS}

O experimento foi realizado no Departamento de Zootecnia (DZO) do Centro de Ciências Agrárias (CCA) da Universidade Federal do Piauí (UFPI), em Teresina-PI. As cascas das vagens foram provenientes do genótipo de feijãofava (Phaseolus lunatus L.) cv. boca-demoça, pertencente ao Banco de 
Germoplasma da UFPI. A pesquisa foi submetida ao Comitê de Ética e Experimentação Animal (CEEA) da Universidade Federal do Piauí e aprovada sob o parecer $015 / 2013$.

A amonização das cascas ocorreu em sacos de polietileno preto, com $2 \mathrm{~kg}$ de MS de casca de feijão-fava tratados por saco, sendo aplicadas 2; 4 e 6\% de ureia, com base na MS. A ureia foi dissolvida em 2 litros de água para elevar o teor de umidade das cascas a 30\% (GOBBI et al., 2008) e, após a aplicação, os sacos foram etiquetados e vedados, permanecendo por 30 dias (ROSA et al., 2000). Decorrido o tempo de tratamento, os sacos foram abertos para aeração natural, por 24 horas (GOBBI et al., 2008), para liberação do excesso de amônia livre no material.

Foram coletadas 4 amostras das cascas amonizadas e não amonizadas para análises químicas, realizadas no Laboratório de Nutrição Animal (LANA) do DZO/CCA/UFPI, em Teresina-PI. As amostras foram moídas em moinho tipo Willey com peneira de malha com crivos 2,0 $\mathrm{mm}$ e submetidas à determinação dos teores de matéria seca (MS) e, com base na MS, proteína bruta $(\mathrm{PB})$, segundo AOAC (2012); e fibra em detergente neutro (FDN) e fibra em detergente ácido (FDA), segundo o método de Van Soest (1991), adaptado por Souza et al. (1999). $\mathrm{O}$ teor de hemicelulose foi estimado pela diferença entre FDN e FDA.

Para avaliação da degradação ruminal, pesou-se $4 \mathrm{~g}$ de amostra em sacos de náilon de $12 \times 8 \mathrm{~cm}$ e porosidade $50 \mu \mathrm{m}$ de acordo com relação de $42 \mathrm{mg} / \mathrm{cm}^{2}$ adotada por Campos et al. (2011). Os sacos foram inseridos no rúmen de três bovinos adultos, providos de cânula ruminal, por $6,12,24,48,72$ e 96 horas (NCR, 2001) e, após o período de incubação, os sacos foram removidos simultaneamente e imersos em recipiente com água gelada, para cessar o processo de fermentação.
A fração prontamente solúvel em água foi determinada imergindo-se os sacos contendo as amostras, em banho-maria a $39^{\circ} \mathrm{C}$, por 1 hora e, juntamente com os sacos dos demais tempos de incubação, foram lavados em máquina de lavar (BRITO et al., 2007), sendo posteriormente pré-secos em estufa com circulação forçada de ar a $65^{\circ} \mathrm{C}$ por $72 \mathrm{~h}$, para posteriores análises quanto aos teores de MS, PB e FDN (VAN SOEST et al., 1991; AOAC, 2012)

Os dados de degradação da MS e PB e a degradação efetiva (DE) foram determinados pelos modelos propostos por Ørskov \& McDonald (1979), $D t=$ $a+b\left(1-e^{-c t}\right)$ e $D E=a+[(b * c)(c+k)]$ respectivamente, em que: $\mathrm{D}_{t}=$ fração degradada no tempo $t(\%) ; a=$ fração solúvel $(\%) ; b=$ fração insolúvel potencialmente degradável; $c=$ taxa de degradação da fração $b\left(h^{-1}\right) ; t=$ tempo (h), $k=$ taxa estimada de passagem das partículas no rúmen $\left(2 ; 5\right.$ e $\left.8 \% \mathrm{~h}^{-1}\right)$. Os parâmetros não lineares $a, b$ e $c$ foram determinados pelo método de GaussNewton, através da fase interativa do Procedimento para Modelos Não Lineares (PROC NLIN) do logiciário estatístico SAS (2000).

Para os valores de degradação da FDN adotou-se, na interpretação, o modelo proposto por Mertens \& Loften (1980), $R t=B^{*} e^{-c t}+I$, em que: $R_{t}=$ fração degradada no tempo $t(\%)$. Procedeu-se a padronização das frações da degradação da FDN pelo modelo proposto por Waldo, Smith \& Cox (1972), $I_{p}=$ $I\left(B_{p}+I\right) * 100$, em que, $B_{p}=$ fração potencialmente degradável padronizada $(\%) ; I_{p}=$ fração indegradável padronizada $(\%) ; B, I=$ como definidas anteriormente. Adotou-se o delineamento de blocos casualizados com parcelas subdivididas nos tempos, sendo os níveis de ureia as subparcelas e três blocos (bovinos fistulados). Foi realizada a análise da variância dos dados e adotado o teste de 
Tukey a 5\% de significância para comparação de médias da degradação da MS, PB e FDN nos tempos de incubação, seguindo-se o procedimento para Modelos Lineares Generalizados (PROC GLM) do logiciário estatístico SAS (2000).

\section{RESULTADOS E DISCUSSÃO}

A amonização resultou em redução no teor de matéria seca (MS) das cascas de vagem de feijão fava, o que decorre da adição de solução aquosa nas mesmas quando do tratamento com ureia (Tabela 1). Houve elevação no teor de proteína bruta (PB), com maiores valores obtidos para os tratamentos com 4 e $6 \%$ de ureia (aumentos de 7,3 e 9,9\% respectivamente), justificado pela adição de nitrogênio não proteico ao subproduto, o que pode melhorar o incremento desse composto para o ambiente ruminal, associado a presença do microrganismos proteolíticos. A formação de proteína microbiana é influenciada diretamente pela disponibilidade de $\mathrm{N}$ na forma de amônia, devido a baixa capacidade de deaminação de alguns nichos de microrganismos ruminais, que necessitam de $\mathrm{N}$ livre para síntese de novo de seus aminoácidos, assim, um incremento nos teores desse constituinte com adição de doses acima de $2 \%$ em cascas de feijãofava mantém os teores de PB acima do recomendado $(7 \%)$ para manutenção de teor mínimo de $\mathrm{N}_{-} \mathrm{NH}_{3}(8 \mathrm{mg} / \mathrm{dl}$ de liquido ruminal) necessária para eficiente fermentação microbiana (PATRA et al., 2013).

Tabela 1. Composição química da casca de feijão-fava (Phaseolus lunatus L.) tratada com ureia (\% na MS)

\begin{tabular}{lcccc}
\hline \multirow{2}{*}{ Composição química } & \multicolumn{4}{c}{ \% de ureia na MS } \\
\cline { 2 - 5 } & $0 \%$ & $2 \%$ & $4 \%$ & $6 \%$ \\
\hline Matéria seca & 88,0 & 71,1 & 72,0 & 70,9 \\
Proteína bruta & 5,8 & 9,5 & 13,2 & 15,7 \\
Fibra em detergente neutro & 77,7 & 77,8 & 77,0 & 75,7 \\
Fibra em detergente ácido & 53,7 & 59,2 & 58,8 & 58,3 \\
Hemicelulose & 24,0 & 18,6 & 21,2 & 17,5 \\
Celulose & 51,47 & 55,31 & 51,79 & 59,42 \\
Lignina & 3,23 & 3,89 & 4,01 & 3,28 \\
\hline
\end{tabular}

Redução nos teores de fibra em detergente neutro foram obtidas apenas com doses de $6 \%$ de ureia, obtendo-se redução nos teores de hemicelulose próximo aos $6 \%$ nesse tratamento. A ação da amônia na fração fibrosa decorre da quebra de ligações éster entre os componentes da parede celular, além de hidratação de expansão de moléculas de celulose e solubilização de compostos mais solúveis como hemicelulose por ruptura de pontes de hidrogênio entre a fração e compostos fenólicos como a lignina (PIRES et al., 2010). Nessa pesquisa a fração lignocelulósica representou maior proporção da FDN (> 50,0\%), o que pode estar associada a menor ação da amônia nessa fração (Tabela 1).

A degradação da matéria seca (DMS) não variou $(\mathrm{P}>0,05)$ com a amonização em até $6 \%$ da MS em todos os tempos de incubação, denotando a não eficácia da amonização nesse nível quanto à DMS da casca de feijão-fava (Tabela 2), no entanto, deve-se considerar que a 
partir de 48 horas, a DMS mostrou-se elevada e acima de $60 \%$, próximo aos obtidos para volumosos como gramíneas.

Os efeitos obtidos nessa pesquisa foram corroborados por Leitão et al. (2005) ao tratarem casca de café (Coffea arabica L.) com até $5 \%$ de ureia, não observando efeitos sobre a DMS, com médias de $48 \%$ para as cascas não tratadas em tempos de incubação acima de 24 horas, e por Andrade \& Quadros (2011) ao tratarem casca de soja com até $12 \%$ de ureia sem efeito da DMS. A ausência de efeito sobre a degradação ruminal com ação da ureia nesses restolhos está associada principalmente as características da parede celular, o que pode limitar seu uso em altas proporções em dietas para ruminantes.

Tabela 2. Degradabilidade da matéria seca, da proteína bruta e da fibra em detergente neutro da casca de feijão-fava tratada com ureia, em função dos períodos de incubação

\begin{tabular}{lccccc}
\hline \multirow{2}{*}{ Fração } & $\begin{array}{c}\text { Período de incubação } \\
\text { (horas) }\end{array}$ & $0 \%$ & $2 \%$ & $4 \%$ & $6 \%$ \\
\cline { 3 - 6 } & 6 & 25,4 & 25,4 & 24,7 & 30,3 \\
& 12 & 42,3 & 39,1 & 37,7 & 41,2 \\
Matéria Seca & 24 & 45,0 & 50,1 & 48,8 & 53,9 \\
& 48 & 60,1 & 61,4 & 61,1 & 64,5 \\
& 72 & 65,9 & 66,0 & 66,0 & 68,0 \\
& 96 & 68,2 & 68,7 & 67,9 & 70,9 \\
\hline & 6 & $42,1^{\mathrm{Ce}}$ & $62,2^{\mathrm{Bc}}$ & $72,9^{\mathrm{Ac}}$ & $78,0^{\mathrm{Ac}}$ \\
Proteína Bruta & 12 & $42,6^{\mathrm{Cd}}$ & $66,8^{\mathrm{Bdc}}$ & $72,2^{\mathrm{Bc}}$ & $76,1^{\mathrm{Ac}}$ \\
& 24 & $54,0^{\mathrm{Cc}}$ & $75,6^{\mathrm{Bb}}$ & $80,9^{\mathrm{ABb}}$ & $83,6^{\mathrm{Abc}}$ \\
& 48 & $65,2^{\mathrm{Bb}}$ & $80,8^{\mathrm{Aab}}$ & $84,7^{\mathrm{Aab}}$ & $87,1^{\mathrm{Aab}}$ \\
& 72 & $74,7^{\mathrm{Ba}}$ & $84,3^{\mathrm{Aa}}$ & $87,3^{\mathrm{Aa}}$ & $90,0^{\mathrm{Aa}}$ \\
Fibra em detergente & $70,1^{\mathrm{Bab}}$ & $85,0^{\mathrm{Aa}}$ & $87,7^{\mathrm{Aa}}$ & $90,4^{\mathrm{Aa}}$ \\
\hline neutro & 6 & 21,5 & 21,0 & 22,0 & 26,6 \\
& 12 & 36,5 & 30,5 & 29,2 & 34,9 \\
& 24 & 40,1 & 44,0 & 42,8 & 43,2 \\
& 48 & 55,5 & 56,0 & 56,0 & 59,6 \\
& 72 & 64,2 & 62,4 & 63,6 & 65,1 \\
& 96 & 65,7 & 64,7 & 64,3 & 67,9 \\
\hline
\end{tabular}

*Médias seguidas por mesma letra, maiúscula nas linhas e minúscula nas colunas, não diferem entre si pelo teste de Tukey a $5 \%$ de probabilidade.

O aumento na DMS ocorreu com o maior tempo de permanência do restolho no ambiente ruminal, com o incremento no tempo de incubação até as $72 \mathrm{~h}$, estabilizando-se a partir deste tempo (Figura 1), comportamento semelhante a alimentos volumosos, que aumentam o tempo de retenção da digesta no ambiente ruminal. 


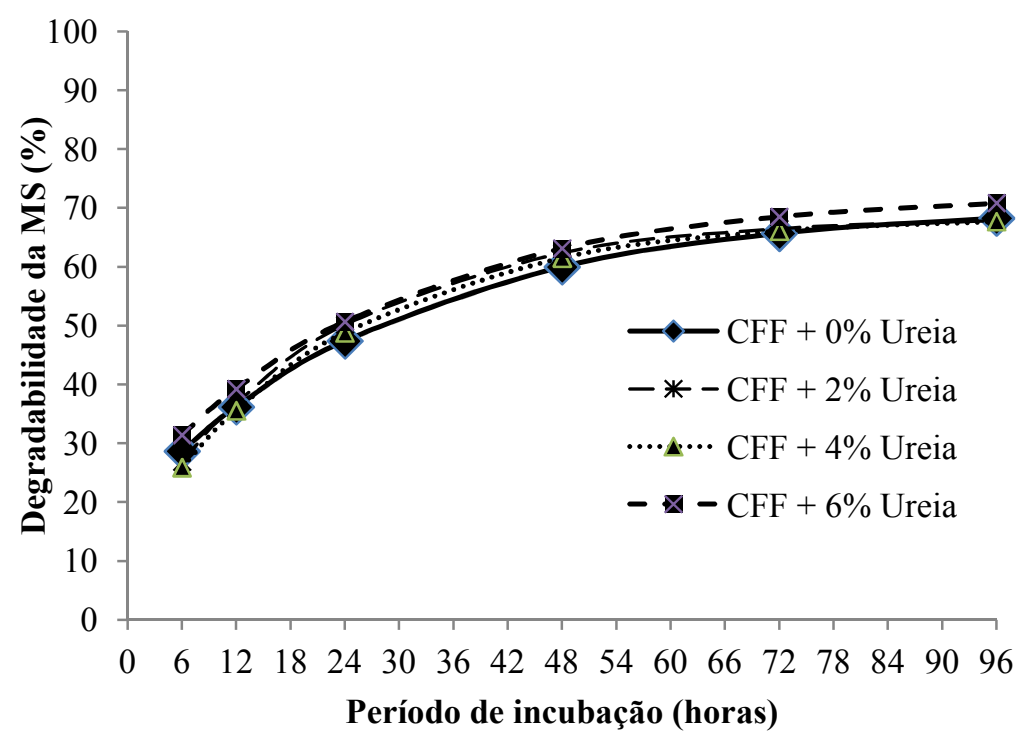

Figura 1. Curvas de degradação da matéria seca (MS) de casca de feijão-fava (Phaseolus lunatus L.) tratada com ureia, em função dos períodos de incubação (horas), ajustadas pelo modelo de Ørskov \& McDonald (1979)

A DMS indica que a casca de feijãofava consiste em alimento volumoso de boa qualidade, considerando que com $48 \mathrm{~h}$ de incubação $85,1 \%$ da degradação potencial da MS das cascas não tratadas já havia sido atingida (Figura 1), motivo pelo qual o efeito da amonização não foi evidenciado. Os valores obtidos para a DMS nessa pesquisa relacionam-se a qualidade do material tratado, visto que forragem de baixo valor nutritivo no momento da amonização, responde melhor aos efeitos do tratamento alcalino devido a melhor ação da amônia sobre a fração fibrosa (PIRES et al., 2010).

A amonização com ureia proporcionou maior $(\mathrm{P}<0,05)$ degradação da $\mathrm{PB}$ (DPB), com média de $74,7 \%$ às $72 \mathrm{~h}$ de incubação, com estabilização a partir deste tempo tanto para casca não tratada quanto amonizada com $2 \%$ de ureia. Para doses mais elevadas de ureia (4 a $6 \%$ a estabilização da DPB foi evidenciada a partir das 48 h (Figura 2), com degradação potencial $91,7 \%$ quando amonizada com $6 \%$ de ureia. A elevada degradação da proteína bruta com amonização de até $6 \%$ está associada ao incremento de NNP no material, pois essa forma de $\mathrm{N}$ é totalmente solubilizada no rúmen $\mathrm{e}$ disponibiliza fontes nitrogenadas para os microrganismos, com maior crescimento e melhoria na degradação da proteína verdadeira presente nas cascas.

A amonização com $6 \%$ de ureia resultou em maior $(\mathrm{P}<0,05)$ degradação da FDN (DFDN) da casca de feijão-fava, com estabilização a partir das $72 \mathrm{~h}$ de incubação no ambiente ruminal, com degradação superior a $63 \%$ em todos os tratamentos, sem influência da amonização com até $6 \%$ de uréia (Tabela 2 e Figura 3). Os valores de degradação obtidos nessa pesquisa estão próximos a volumosos disponíveis nos trópicos, inclusive fenos de gramíneas (CARVALHO et al., 2006; OLIVEIRA et al., 2013). 


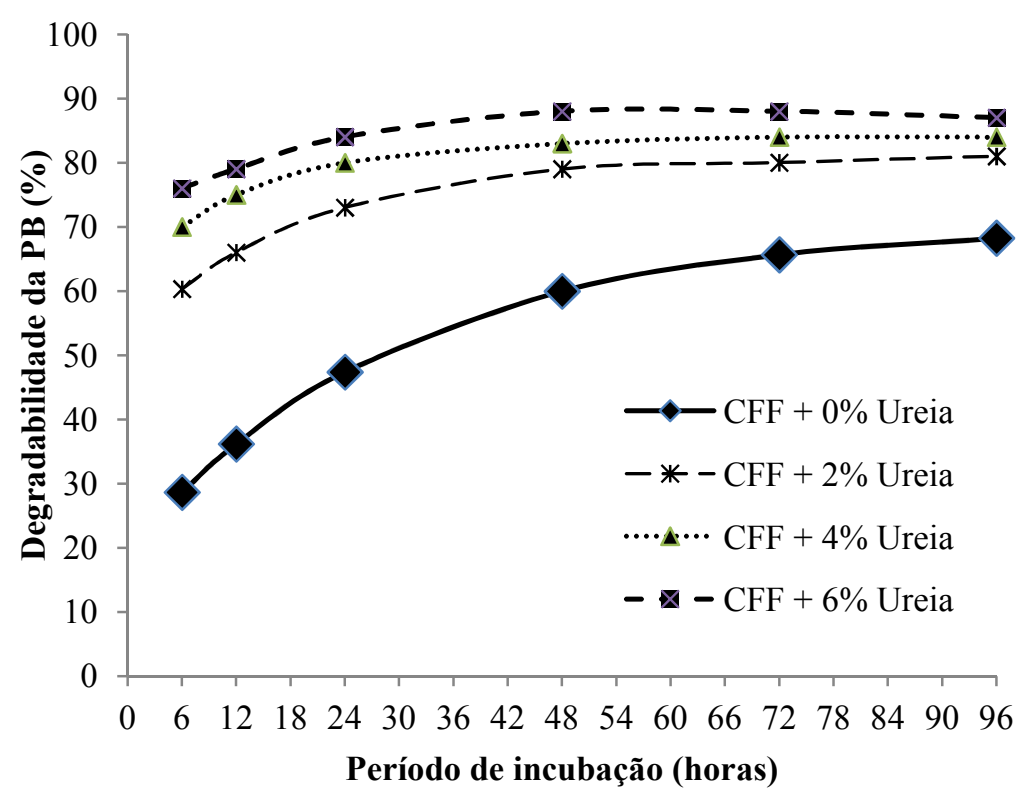

Figura 2. Curvas de degradação da proteína bruta (PB) de casca de feijão-fava (Phaseolus lunatus L.) tratada com ureia, em função dos períodos de incubação (horas), ajustadas pelo modelo de Ørskov e McDonald (1979)

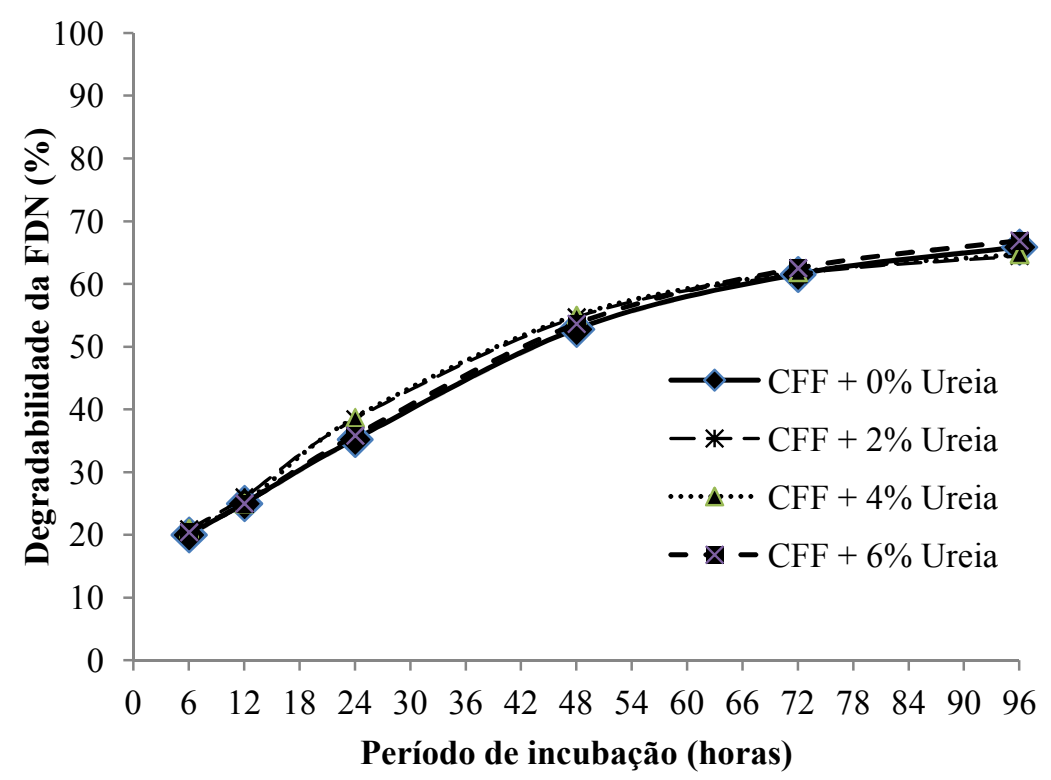

Figura 3. Curvas de degradação da fibra em detergente neutro (FDN) de casca de feijão-fava (Phaseolus lunatus L.) tratada com ureia, em função dos períodos de incubação (horas), ajustadas pelo modelo de Ørskov \& McDonald (1979) 
Quando da ação sobre os componentes da fração fibrosa, a amônia pode agir como álcali, promovendo quebras entre polímeros de ligações do tipo éster, de estruturas de carboidratos que compõem a parede celular, agindo, também, no aumento da hidratação das partículas ou por formar um complexo com a celulose, rompendo pontes de hidrogênio, consequentemente, reduzindo sua cristalinidade, facilitando maior degradação microbiana das partículas (PIRES et al., 2010), sendo este ultimo efeito menos pronunciado nessa pesquisa (Tabela 1).

Quanto aos parâmetros de cinética da degradação ruminal da MS, fração solúvel (a), fração potencialmente degradável $(b)$ e taxa de degradação da fração $b(c)$, a amonização com doses crescentes de ureia não promoveu incrementos (Tabela 3), o que resultou também em pouca variação nas degradabilidades potencial (DP) e efetiva (DE) da MS para as taxas de passagem 2; 5 e $8 \% \mathrm{~h}^{-1}$ (Tabela 4 ), no entanto os valores obtidos para essa fração são elevados para um subproduto caracterizado como alimento volumoso.
A baixa degradação potencial da MS e a ausência de efeito da amonização nessa fração pode estar associada ao elevado teor de FDN do alimento, que corresponde a mais de $70 \%$ da matéria seca (Tabela 1), associada a reduzida ação da amônia em reduzir a fração fibrosa das cascas tratadas. Os valores obtidos nessa pesquisa para a DP da MS da casca de feijão-fava $(70,0 \% \pm 1,7)$ aproximam-se dos obtidos por Moreira filho et al. (2013) para o feno de restolho da cultura do milho $(71,5 \%)$, por Carvalho et al. (2006) para fenos dos capins colonião $(71,07 \%)$, Tifton $(71,38 \%)$ e braquiária $(73 \%)$.

Quanto aos parâmetros da cinética ruminal da $\mathrm{PB}$, a solubilidade (fração $a$ ) da casca de feijão-fava aumentou em $60 \%$ quando da amonização com $6 \%$ de ureia (Tabela 3). Estes valores podem ser atribuídos à elevação do teor de NNP na casca de feijão-fava quando da amonização com ureia, sendo essa imediatamente solubilizada no rúmen e utilizada para a síntese de proteína microbiana, com maior crescimento da microbiota proteolítica e degradação das demais fontes proteicas.

Tabela 3. Parâmetros da cinética de degradação ruminal da matéria seca, da proteína bruta de casca de feijão-fava (Phaseolus lunatus L.) tratada com ureia

\begin{tabular}{ccccc}
\hline \multirow{2}{*}{ Percentagem de ureia (\%) } & \multicolumn{3}{c}{ Parâmetros } & \multirow{2}{*}{$\mathrm{R}^{2}$} \\
\cline { 2 - 4 } & $\mathrm{a}(\%)$ & $\mathrm{b}(\%)$ & $\mathrm{c}\left(\% / \mathrm{h}^{-1}\right)$ & \\
\hline \multicolumn{5}{c}{ Degradação da matéria seca } \\
\hline 0 & 23,9 & 46,5 & 3,30 & 93,8 \\
2 & 22,4 & 46,1 & 4,50 & 94,6 \\
4 & 23,7 & 44,9 & 4,30 & 98,1 \\
6 & 25,5 & 47,2 & 3,50 & 96,7 \\
\hline \multicolumn{5}{c}{ Degradação da proteína bruta } \\
\hline 0 & 47,0 & 30,5 & 3,70 & 93,2 \\
2 & 59,8 & 25,2 & 4,50 & 90,1 \\
6 & 69,9 & 18,7 & 4,70 & 92,7 \\
\hline \multicolumn{5}{c}{} \\
\hline
\end{tabular}


Tabela 4. Degradabilidade potencial (DP) e efetiva (DE) da matéria seca, da proteína bruta e da fibra em detergente neutro de casca de feijão-fava (Phaseolus lunatus L.) tratada com ureia, calculadas para taxas de passagem $2 ; 5$ e $8 \% \mathrm{~h}-1$

\begin{tabular}{|c|c|c|c|c|}
\hline \multirow{2}{*}{ Percentagem de ureia (\%) } & \multirow{2}{*}{$\mathrm{DP}$} & \multicolumn{3}{|c|}{ DE (taxa de passagem, $\% \mathrm{~h}^{-1}$ ) } \\
\hline & & 2 & 5 & 8 \\
\hline \multicolumn{5}{|c|}{ Degradabilidade da matéria seca } \\
\hline 0 & 70,4 & 52,9 & 42,4 & 37,5 \\
\hline 2 & 68,5 & 54,4 & 44,4 & 39,1 \\
\hline 4 & 68,6 & 54,3 & 44,4 & 39,3 \\
\hline 6 & 72,6 & 55,5 & 44,9 & 39,8 \\
\hline \multicolumn{5}{|c|}{ Degradabilidade da proteína bruta } \\
\hline 0 & 77,5 & 64,3 & 57,5 & $\overline{54,6}$ \\
\hline 2 & 85,0 & 77,2 & 71,7 & 68,8 \\
\hline 4 & 88,6 & 82,0 & 77,8 & 75,8 \\
\hline 6 & 91,7 & 84,9 & 81,2 & 79,5 \\
\hline \multicolumn{5}{|c|}{ Degradabilidade da fibra em detergente neutro } \\
\hline 0 & 70,2 & 33,6 & 18,8 & 13,1 \\
\hline 2 & 66,6 & 59,4 & 44,4 & 37,5 \\
\hline 4 & 66,9 & 54,3 & 39,5 & 33,4 \\
\hline 6 & 71,3 & 66,2 & 50,2 & 42,9 \\
\hline
\end{tabular}

A taxa de degradação ruminal da fração proteica manteve-se acima de $3 \%$ em todos os tratamentos, com maiores valores quando da amonização com $4 \mathrm{e}$ $6 \%$. Melhorias na taxa de degradação de frações nitrogenadas aumentam a disponibilidade $\mathrm{N}$ para síntese de proteína microbiana, principalmente por bactérias celulolíticas, e consequentemente a população, maximizando o mecanismo de colonização por fornecer compostos que facilitam ação das adesinas da parede celular, levando a elevação nas taxas de degradação da fração fibrosa da ração (ROCHA et al., 2006).

A degradabilidade efetiva (DE) da proteína bruta mostrou-se elevada, variando em função da taxa de passagem, sendo maior à taxa de passagem $2 \% \mathrm{~h}^{-1}(84,9 \%)$ e menor à taxa de passagem $8 \% \mathrm{~h}^{-1}(79,5 \%)$ (Tabela 4). Este resultado pode ter decorrido da disponibilidade de NNP proveniente da ureia aos microrganismos do rúmen aliada à alteração da parede celular pela amonização, facilitando a degradação pelas bactérias ruminais. A degradação da PB reflete além da disponibilidade de compostos nitrogenados a nível ruminal, o teor de aminoácidos que chegam ao intestino, provenientes da fração proteica dietética não degradada no rúmen.

Quanto aos parâmetros da cinética de degradação ruminal da FDN, a amonização com $6 \%$ de ureia reduziu em cerca de 1 hora o tempo de latência (lag time), embora este efeito não tenha influenciado os demais parâmetros da cinética de degradação ruminal da FDN (Tabela 5), devido à elevada proporção da fração potencialmente degradável no rúmen $\left(B_{p}\right)$ associada à boa degradação deste constituinte (maior que 60\%) e taxa de degradação compatível com as características de alimentos volumosos, média de $3,3 \% \mathrm{~h}^{-1}$. 
Tabela 5. Parâmetros da cinética de degradação ruminal da fibra em detergente neutro (FDN) de casca de feijão-fava (Phaseolus lunatus L.) sob diferentes doses de ureia

\begin{tabular}{lccccc}
\hline \multirow{2}{*}{ Percentagem de ureia (\%) } & \multicolumn{4}{c}{ Parâmetros } & $\mathrm{R}^{2}$ \\
\cline { 2 - 6 } & $\operatorname{lag}(\mathrm{h})^{1}$ & $\mathrm{~B}_{\mathrm{p}}(\%)$ & $\mathrm{I}_{\mathrm{p}}(\%)^{2}$ & $c\left(\%^{-1}\right)^{3}$ & \\
\hline 0 & 5,7 & 70,2 & 29,8 & 0,029 & 98,1 \\
2 & 5,4 & 66,6 & 33,4 & 0,036 & 95,9 \\
4 & 5,6 & 66,9 & 33,1 & 0,036 & 97,9 \\
6 & 4,5 & 71,3 & 28,7 & 0,029 & 96,7 \\
\hline${ }^{1}$ lag=tempo de colonização; B $_{\mathrm{p}}=$ fração insolúvel potencialmente degradável; ${ }^{2} \mathrm{I}_{\mathrm{p}}=$ fração \\
indegradável; ${ }^{3} \mathrm{c}$ = taxa de degradação da fração B; R ${ }^{2}=$ coeficiente de determinação.
\end{tabular}

Os valores para fração potencialmente degradação foram superiores aos obtidos por Garcez et al. (2014) para feno de folíolos de pindoba de babaçu, com média de $28,30 \%$ para amonização com $4 \%$ de ureia e por Muniz et al. (2012) obtendo valores de 31\% para feno de mata-pasto (Senna obtusifolia L.), e $28,91 \%$ para mororó (Bauhinia cheilanta). A fração indegradável da FDN (Ip) apresentou valores próximos as 30\% da fração fibrosa, o que pode ser o principal determinante da alta DP da MS.

Em termos nutricionais, deve-se considerar que todos os eventos de ação microbiana nas frações potencialmente degradáveis e indegradáveis da FDN dependem do tempo no qual a interação enzima com substrato ocorre, ou seja, da efetividade do processo de degradação, relacionado diretamente ao tempo de colonização microbiana (DETMANN et al., 2007). Bactérias celulolíticas são exigentes em termos de nutrientes oriundos da dieta, assim, a alta degradação da fração proteica nessa pesquisa influenciou positivamente $\mathrm{o}$ tempo de colonização por melhoria na colonização e maior crescimento desses microrganismos, com melhor aproveitamento da fração fibrosa.

A casca de feijão-fava apresenta elevada taxa de degradação, consistindo em um alimento volumoso de boa qualidade, apesar de consistir resíduo de cultura. A amonização de casca de feijão-fava com ureia não promove melhoria na degradabilidade da matéria seca, embora proporcione elevação do teor de nitrogênio total disponível aos microrganismos do rúmen e melhore a degradabilidade da fibra em detergente neutro, sendo o nível de $6 \%$ mais indicado para o tratamento desse volumoso.

\section{REFERÊNCIAS}

AMARAL, G.M.; FONTANA, F.; GASPER, A.L.; FREITAS, D.S.; LUCIA, S. Aspects of distribution of Mimosoideae (Fabaceae) trees in the highlands of Santa Catarina, southern Brazil. Neotropical Biology and Conservation, v.10, n.2, p.74-84, 2015.

ANDRADE, A.P.; QUADROS, D.G. Composição bromatológica da casca de soja amonizada com ureia. Revista de Biologia e Ciências da Terra,v.11, n.1, p.38-46, 2011.

ASSOCIATION OF ANALYTICAL COMMUNITIES - AOAC. Official methods of analysis of $\mathrm{AOAC}$ international. 19th.ed. Gaithersburg, MD, USA: Association of Analytical Communities, 2012. 2610p. 
BRITO, M.R.; SAMPAIO, A.A.M.; FERNANDES, A.R.M.; HENRIQUE, W.; CATTELAN, J.W.; ROUTMAN, K.S. Degradabilidade in situ e parâmetros ruminais em bovinos alimentados com dietas balanceadas para diferentes ganhos de peso e potenciais de fermentação microbiana. Revista Brasileira de Zootecnia, v.36, n.5, p.1639-1650, 2007.

CAMPOS, M.M.; BORGES, A.L.C.C.; LOPES, F.C.F. PANCOTI, C.G.; REIS E SILVA, R. Degradabilidade in situ da cana-de-açúcar tratada ou não com óxido de cálcio, em novilhas leiteiras Holandês x Gir. Arquivo Brasileiro de Medicina Veterinária e Zootecnia, v.63, n.6, p.1487-1492, 2011.

CARVALHO, G.G.P.; PIRES, A.J.V.; VELOSO, C.M.; SILVA, F.F.; SILVA, R.R. Degradabilidade ruminal do feno de forragens tropicais. Revista

Brasileira de Agrociências, v.12, n.1, p.81-85, 2006.

DETMANN, E.; VALADARES FILHO, S.C.; HENRIQUES L.T.; PINA, D.S.; PAULINO, M.F.; MAGALHÃES, A.L.R.; PORTO, M.O.; CHIZZOTI, M.L. Reparametrização do modelo baseado na lei de superfície para predição da fração digestível da fibra em detergente neutro em condições brasileiras. Revista Brasileira de Zootecnia, v.36, n.1, p.155-164, 2007.

GARCEZ, B.S.; ALVES, A.A.; OLIVEIRA, M.E.; PARENTE, H.N.; SANTANA, Y.A.G.; MOREIRA FILHO, M.A.; CÂMARA, C.S. Valor nutritivo do feno de folíolos de pindoba de babaçu submetido a tratamentos alcalinos. Ciência Rural, v.44, n.3, p.524-530, 2014.
GOBBI, K.F.; GARCIA, R.;

VENTRELLA, M.C.; GARCEZ NETO, A.F.; PEREIRA, O.G. Leaf tissues degradation of signalgrass hay pretreated with urea and submitted to in vitro digestion. Revista Brasileira de Zootecnia, v.37, n.5, p.802-809, 2008.

LEITÃO, R.A.; PAIVA, P.C.A de; REZENDE, C.A.P.; VON TIESENHAUSEN, I.M.E.V.; CARDOSO, R.M.; GONÇALVES, T.M. Valor nutritivo da casca de café (Coffea arabica 1.) Tratada com hidróxido de sódio e/ou ureia suplementada com feno de alfafa (Medicago sativa 1.). Pesquisa Agropecuária Tropical, v.35, n.1, p.31-36, 2005.

MERTENS, D.R.; LOFTEN, J.R. The effects of starch on forage fiber digestion kinetics in vitro. Journal of Dairy Science, v.63, n.5, p.1437-1446, 1980.

MOREIRA FILHO, M.A.; ALVES, A.A.; VALE, G.E.S.; MOREIRA, A.L.; ROGERIO, M.C.P. Valor nutritivo do feno de restolho da cultura do milho amonizado com ureia. Revista Ciência Agronômica, v.44, n.4, p.893-901, 2013.

MUNIZ, E.B.; MIZUBUITI, I, Y.; PEREIRA, E.S.; PIMENTEL, P.G.; RIBEIRO, E.L.A.; PINTO, A.P. Cinética ruminal da fração fibrosa de volumosos para ruminantes. Revista Ciência Agronômica, v.43, n.3, p.604610, 2012.

NATIONAL RESEARCH COUNCIL NRC. Nutrient requirements of dairy cattle. 7 th rev. ed. Washington, D.C.: National Academy Press, 2001. 381p. 
OLIVEIRA, E.R.; MONÇÃO, F.P.; GOES, R.H.T.B.; GABRIEL, A.M.A.; MOURA, M.V.; LEMPP, B.;

GRACIANO, D.E.; TOCHETTO, A.T.C. Degradação ruminal da fibra em detergente neutro de gramíneas do gênero Cynodon spp em quatro idades de corte. Revista Agrarian, v.6, n.20, p.205-214, 2013.

ØRSKOV, E. R.; McDONALD, I. The estimation of protein degradability in the rumen from incubation measurements weighted according to rate of passage. The Journal of Agricultural Science, v.92, n.2, p.499503, 1979.

PATRA, A.K. Urea/Ammonia Metabolism in the Rumen and Toxicity in Ruminants. In: PUNYIA, A.K.; SIEGH, R.; KAMICA, D.M. Rumen Microbiology: from evolution to revolution. India: Springer, 2013. p.329341.

PIRES, A.J.V.; CARVALHO, G.G.P.; RIBEIRO, L.S.O. Chemical treatment of roughage. Revista Brasileira de Zootecnia, v.39, p.192-203, 2010. (Suplemento especial).

ROCHA, F.C.; GARCIA, R.; FREITAS, A.W.P.; BERNADINO, F.S.; ROCHA, G.C. Amonização sobre a composição química e digestibilidade da silagem de capim-elefante. Revista Ceres, n.53, v.306, p.228-233, 2006.

ROSA, B.; SOUZA, H.; RODRIGUEZ, K.F. Composição química do feno de Brachiaria brizantha cv. Marandu tratado com diferentes proporções de ureia e de água. Ciência Animal Brasileira, v.1, n.2, p.107-113, 2000.

SAS INSTITUTE. SAS/STAT user's guide statistics. Version 8. Cary: SAS Institute, 2000.
SILVA, D. J.; QUEIROZ, A. C. Análise de alimentos: métodos químicos e biológicos. 3.ed., Viçosa: UFV, 2006. 235p.

SOUZA, A.L.; GARCIA, R.; PEREIRA, O.G.; CECON, P.R.; VALADARES FILHO, S.C.; SOUZA, G.B. Método alternativo para determinação de fibra em detergente neutro e detergente ácido. São Carlos: Embrapa Pecuária Sudeste, 1999. 21p. (Boletim de Pesquisa, 4).

SULTANA, N.; ALIMON, A.R.; HUQUE, K.S.;SAZILI, A.Q.; YAAKUB, H.; HOSSAIn, J.; BABA, $M$. The Feeding Value of Moringa (Moringa Oleifera) Foliage as Replacement to Conventional Concentrate Diet in Bengal Goats. Advances in Animal and Veterinary Sciences, v.3, n.3, p.164-173, 2015.

WALDO, D.R.; SMITH, L.W.; COX, L.E. Model of cellulose disappearance from the rumen. Journal of Dairy Science, v.55, n.1, p.125-129, 1972.

Data de recebimento: $23 / 04 / 2015$ Data de aprovação: 05/12/2016 